\title{
The recollective experience of cross-modality confusion errors
}

\author{
SEAN M. LANE and MARIA S. ZARAGOZA \\ Kent State University, Kent, Ohio
}

\begin{abstract}
There are at least two qualitatively different types of subjective experience that can accompany accurate recognition memory. Sometimes recognition is accompanied by conscious recollection of the learning episode (i.e., it is remembered), and in other cases it is not (i.e., it is simply known that the item is old). In the present study, we assessed the subjective experience that accompanies crossmodality confusion errors (misidentifying words as pictures) by measuring the extent to which subjects claimed to remember versus know that the item was presented as a picture. The results of two experiments demonstrate that cross-modality confusion errors are often accompanied by conscious recollection, although not to the same extent as accurate memories. The findings also show that there is considerable overlap in the recollective experience that accompanies accurate and erroneous memories. Finally, the results support the contention that recollective experience cannot be directly inferred from test performance.
\end{abstract}

The systematic investigation of conscious recollective experience is a relatively new development in memory research. Only recently have researchers attempted to directly assess the subjective experience that accompanies remembering rather than inferring the nature of conscious experience from memory performance (Tulving, 1985). One of the most important discoveries to emerge from this research concerns the lack of correspondence between memory performance and conscious experience. For example, there is considerable evidence that accurate recognition performance can be accompanied by at least two distinct forms of recollective experience (e.g., Gardiner 1988; Rajaram, 1993). Sometimes recognition is accompanied by conscious recollection of the learning episode (hereafter referred to as remembering), and in other cases it is not (hereafter referred to as knowing).

The absence of a clear relationship between accurate memory performance and recollective experience raises a number of interesting questions about the subjective experience that accompanies confusion errors in memory: Might the subjective experience that accompanies erroneous memories differ from that which accompanies veridi-

The experiments reported in this article constituted a master's thesis submitted by Sean Lane to Kent State University. Preparation of this article was supported in part by National Institute of Mental Health Grant MH47858-01A1 to M.S. Z. Part of this research was presented at the 1993 meeting of the Midwestern Psychological Association in Chicago. We would like to thank thesis committee members Bill Merriman, Joseph Danks, and Yossef Ben-Porath, as well as Jonathan Schooler, Geoffrey Loftus, and an anonymous reviewer, for their comments on an earlier version of this manuscript. We would like to acknowledge Marcia Barber and Paul Binion for their assistance with data collection. Correspondence concerning this article should be addressed to $\mathrm{S}$. Lane, Department of Psychology, University of Nevada, Las Vegas, NV 89154-5030 (e-mail: slane@nevada.edu). cal ones? Or might the subjective experience of erroneous memories be similar to that of accurate memories?

The goal of the present study was to assess the subjective experience that accompanies cross-modality confusion errors - specifically, cases in which verbal information is misremembered as having been presented in the form of a picture. These sorts of errors are fairly easy to induce (e.g., Durso \& Johnson, 1980; Rosenberg \& Simon, 1977), and may be commonplace in everyday life. Moreover, susceptibility to cross-modality confusion errors may have serious practical consequences, such as when eyewitnesses confuse misleading postevent suggestions for events they actually witnessed (e.g., Loftus, Miller, \& Burns, 1978; Zaragoza \& Lane, 1994). We report two experiments in which subjects received a mixed list of pictures and words under two orienting conditions that have been shown to induce cross-modality confusion errors (Durso \& Johnson, 1980). All subjects received a test for modality of presentation after a 24 -h retention interval. The experiments were designed to assess the subjective experience that accompanied memory for pictures, as a function of whether the memory was in error or not. Of primary interest was a comparison of the subjective experience that accompanied word-to-picture confusion errors with that which accompanied accurate memories of pictures.

To assess subjective experience, we employed a modified version of the remember/know procedure first developed by Tulving (1985). Specifically, for each item that subjects identified as a picture, they were asked to indicate whether they remembered seeing it as a picture (defined as the ability to consciously recollect seeing an item as a picture) or whether they simply knew the item had been presented as a picture (defined as believing an item had been shown as a picture but not being able to consciously recollect the learning episode). 
The experiments were designed to answer three questions: (1) Are word-to-picture confusion errors ever accompanied by conscious recollection (albeit illusory) of an actual picture? If so, (2) are these confusion errors accompanied by conscious recollection of pictures to the same extent as accurate memories? And (3) are cross-modality confusion errors more likely to be accompanied by conscious recollection of pictures to a greater extent than false identifications that arise for other reasons (e.g., new items that are incorrectly identified as pictures)? Because the methods and results of the two experiments are very similar, they will be discussed together.

\section{METHOD}

\section{Subjects}

A total of 96 undergraduates ( 48 subjects in each of Experiments 1 and 2) participated for course credit. ${ }^{1}$

\section{Materials}

The stimuli were 144 items taken from the Snodgrass and Vanderwart (1980) norms. For each item, both a word and a picture version was prepared and each version was mounted on a $5 \times 8$ card. During the encoding phase, one third of these items were presented as pictures, one third were presented as words, and one third were not presented at all (these items functioned as lures on the final test). Across the experiment, each item served equally often as a word, a picture, and a lure.

\section{Design and Procedure}

The participants were tested individually. The list of 96 study items was presented in two blocks of 48 items, with one block studied under the function orienting task (the subjects had to state a use for each item) and another studied under the artist orienting task (the subjects had to rate, on a 1-10 scale, how long it would take to draw the picture or the word's referent). Across each experiment presentation order of the orienting task was counterbalanced, and there were equal numbers of pictures and words in each orienting condition. The order of these pictures and words was randomized for each subject by shuffling the index cards, with the restriction that no more than two words or pictures be shown consecutively. Each card was shown for approximately $2 \mathrm{sec}$ and the name of the item was said aloud by the experimenter. After completing the orienting tasks, the subjects were dismissed and instructed to return the following day.

Experiment 1. On Day 2, the subjects in Experiment 1 were told that they were going to receive a memory test for the pictures and words they had seen the day before. They were told that the experimenter would read a list of 144 items aloud, and that for each item they were to mark the yes column on their answer sheet if it had been presented as a picture, and the no column if it had not. Subjects were informed that the test list consisted of the pictures and words they had seen the day before, along with some new (never-presented) items. After subjects completed the test, they were asked to make remember/know judgments for each item they had identified as a picture (the complete instructions are reproduced in the Appendix). To ensure that the subjects understood the instructions, they were required to briefly justify each remember/know response.

Experiment 2. The subjects in Experiment 2 were treated identically, with the following exceptions: (1) they made judgments about subjective experience simultaneously, with their modality judgments; (2) their instructions for remember/know judgments differed slightly (see the Appendix); and (3) they were given an opportunity to indicate if they were "not sure."2 For each test item, the subjects were asked to indicate which of the following four response options best described their memory by checking the appropriate column on their answer sheet: (1) Remember as a picture, (2) Know it was a picture; (3) Not sure, and (4) Not a picture.

\section{RESULTS $^{3}$}

Not surprisingly, in both experiments, the subjects made more accurate identifications than cross-modality confusion errors, and more confusion errors than false alarms to lures (see Tables 1-2). In order to compare subjective experience across response type, the proportion of remember judgments in each response category was used as the dependent measure.

As is clear from Figures 1 and 2, the major findings from both experiments are: (1) Pictures accurately identified as pictures at test were more often accompanied by remember responses than were words incorrectly identified as pictures at test $\left[F(1,47)=112.4, M S_{\mathrm{e}}=.02, p<.01\right.$, and $F(1,47)=41.7, M S_{\mathrm{e}}=.03, p<.01$, for Experiments 1 and 2, respectively]; and (2) words incorrectly identified as pictures were more often accompanied by remember responses than were lures incorrectly identified as pictures $\left[F(1,47)=21.8, M S_{\mathrm{e}}=.05, p<.01\right.$, and $F(1,47)=23.7$, $\left.M S_{\mathrm{e}}=.06, p<.01\right) .{ }^{4}$ When the performance of individual subjects was examined, the same pattern was observed. ${ }^{5}$ The results of both experiments thus support the conclusion that accurate memories are more often accompanied by conscious recollection than are confusion errors, while confusion errors are more often accompanied by conscious recollection than are false-alarm errors.

\section{DISCUSSION}

A primary goal of this study was to assess the subjective experience that accompanies cross-modality confusion errors in memory. The results of these experiments provide the first evidence that subjects who misremember words as pictures often base this judgment on a conscious

Table 1

Proportion of Responses Per Category as a Function of Mode of Presentation at Study in Experiment 1

\begin{tabular}{|c|c|c|c|}
\hline \multirow[b]{2}{*}{$\begin{array}{l}\text { Mode at } \\
\text { Study }\end{array}$} & \multicolumn{3}{|c|}{ Test Response Category } \\
\hline & $\begin{array}{c}\text { Picture + } \\
\text { Remember }\end{array}$ & $\begin{array}{c}\text { Picture + } \\
\text { Know }\end{array}$ & $\begin{array}{c}\text { Not a } \\
\text { Picture }\end{array}$ \\
\hline Picture & .52 & .11 & .29 \\
\hline Word & .14 & .17 & .69 \\
\hline Not presented & .02 & .05 & .93 \\
\hline
\end{tabular}

Note-Proportions are rounded up to the nearest hundredth.

Table 2

Proportion of Test Reponses as a Function of Mode of Presentation at Study in Experiment 2

\begin{tabular}{lcccc}
\hline & \multicolumn{4}{c}{ Type of Test Response } \\
\cline { 2 - 5 } \multicolumn{1}{c}{$\begin{array}{c}\text { Mode at } \\
\text { Study }\end{array}$} & $\begin{array}{c}\text { Picture }+ \\
\text { Remember }\end{array}$ & $\begin{array}{c}\text { Picture }+ \\
\text { Know }\end{array}$ & $\begin{array}{c}\text { Not } \\
\text { Sure }\end{array}$ & $\begin{array}{c}\text { Not a } \\
\text { Picture }\end{array}$ \\
\hline Picture & .56 & .11 & .09 & .24 \\
Word & .13 & .07 & .10 & .71 \\
Not presented & .02 & .03 & .14 & .81 \\
\hline
\end{tabular}

Note--Proportions are rounded up to the nearest hundredth. 


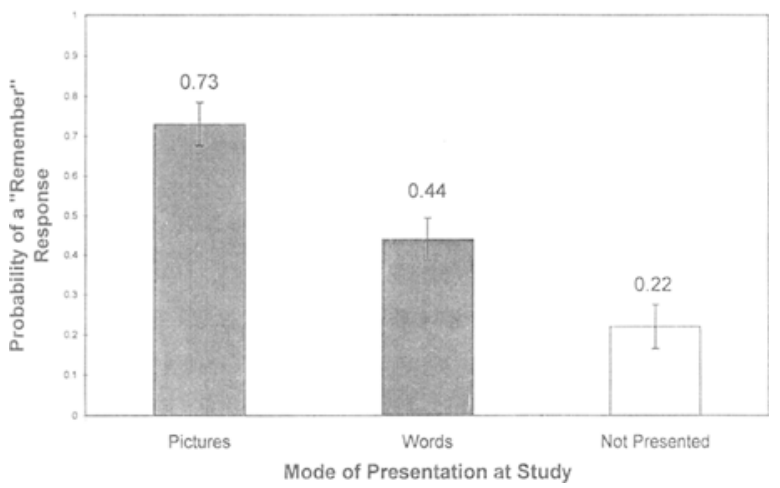

Figure 1. Experiment 1: Mean probability of a remember response for items that were identified as pictures at test as a function of whether the item was presented as a picture at study (correct identification), presented as a word during study (cross-modality confusion), or not presented (false alarm).

\section{Experiment 2}

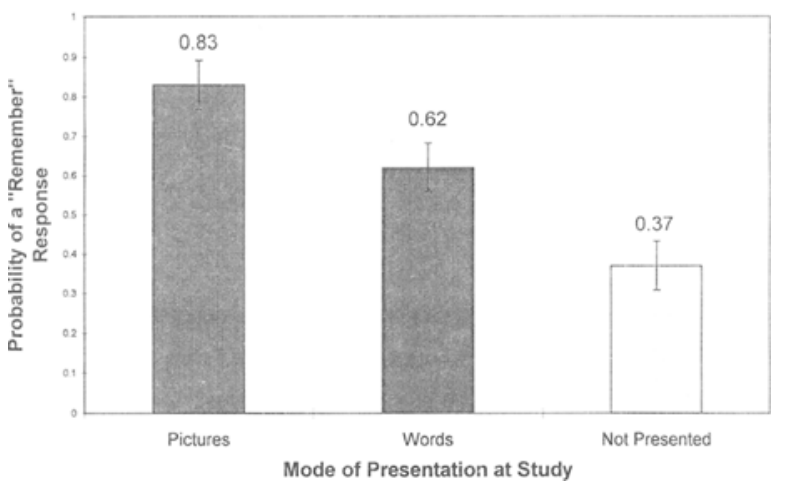

Figure 2. Experiment 2: Mean probability of a remember response for items that were identified as pictures at test as a function of whether the item was presented as a picture at study (correct identification), presented as a word during study (cross-modality confusion), or not presented (false alarm).

recollection of what the item looked like. A second goal of this study was to compare the subjective experience that accompanies accurate and erroneous memories, as assessed by the relative proportion of remember-it-was-a-picture versus know-it-was-a-picture judgments. The clear and consistent finding in both experiments was that memories of pictures that were based on cross-modality confusions were not accompanied by conscious recollection to the same extent as memories based on actually perceived pictures. These differences notwithstanding, a more provocative finding from our point of view is the fact that, at least insofar as the remember $/$ know distinction is concerned, there was nothing in the subjects' subjective experience that uniquely distinguished accurate memories from erroneous ones: both memories of actually perceived pictures and memories resulting from cross-modality confusion were sometimes remembered and sometimes simply known; similarly, both types of memories were more likely to be remembered than known. Hence, neither remembering nor knowing was uniquely diagnostic with regard to the actual truth of a memory. Of course, the re- member/know distinction may not capture all of the dimensions on which the subjective experience of memories may differ - it is conceivable that accurate and erroneous memories did differ on some qualitative characteristic that we were simply unable to measure. Nevertheless, the results of the present study suggest that there is considerable overlap between the subjective experience of accurate and erroneous memories.

\section{REFERENCES}

Durso, F. T., \& JoHnson, M. K. (1980). The effects of orienting tasks on recognition, recall, and modality confusion of pictures and words. Journal of Verbal Learning \& Verbal Behavior, 19, 416-429.

GARDINER, J. M. (1988). Functional aspects of recollective experience. Memory \& Cognition, 16, 309-313.

LofTus, E. F., Miller, D. G., \& BurNs, H. J. (1978). Semantic integration of verbal information into visual memory. Journal of Experimental Psychology: Human Learning \& Memory, 4, 19-31.

RaJARAM, S. (1993). Remembering and knowing: Two means of access to the personal past. Memory \& Cognition, 21, 89-102.

RosenberG, S., \& Simon, H. A. (1977). Modeling semantic memory: Effects of presenting semantic information in different modalities. Cognitive Psychology, 9, 293-325.

SNODGRass, J. G., \& VANDERWART, M. (1980). A standardized set of 260 pictures: Norms for name agreement, image agreement, familiarity, and visual complexity. Journal of Experimental Psychology: Human Learning \& Memory, 11, 174-215.

Tulving, E. (1985). Memory and consciousness. Canadian Psychologist, 26, 1-12.

ZARAGOZA, M. S., \& LANE, S. M. (1994). Source misattributions and the suggestibility of eyewitness memory. Journal of Experimental Psychology: Learning, Memory, \& Cognition, 20, 934-945.

\section{NOTES}

1. In Experiment 1, three subjects were replaced for inappropriately applying the remember/know distinction, as indicated by their brief justification for their answers. In Experiment 2, one subject was replaced for this reason, and another was replaced due to experimenter error.

2 . One concern in studies employing the remember/know methodology is that subjects might equate remembering with high confidence and knowing with low confidence. In Experiment 2, we added not sure as a response alternative in an attempt to make more explicit the distinction between confidence in a memory and the ability to consciously recollect details of the learning episode.

3. Although the artist task led to more cross-modality confusion errors than the function task $\left[F(1,47)=32.3, M S_{\mathrm{e}}=4.8, p<.01\right.$ and $F(1,47)=$ $13.3, M S_{\mathrm{e}}=4.4, p<.01$, for Experiments 1 and 2, respectively), in both experiments and across all response categories, the distribution of remember and know judgments never varied as a function of orienting condition (all $p s>.05$ ). Hence, we report the data collapsed across the two orienting conditions.

4. In Experiment 1, eight subjects did not make a false-alarm error and in Experiment 2, 1 subject did not make a cross-modality confusion and 10 subjects did not make a false-alarm error. The pattern of results is identical when these subjects are excluded from the analysis.

5. For example, in Experiment 1, 45 subjects made a higher proportion of remember responses when they were accurate than when they made a cross-modality confusion (sign test, $z=5.91$, two-tailed, $p<.01$ ). In addition, 31 out of 40 subjects ( 8 subjects did not make a false-alarm error) made a higher proportion of remember responses when they made confusion errors than when they made a false-alarm error $(z=3.32$, twotailed, $p<.01$ ). Similar results were obtained for Experiment 2 .

\section{APPENDIX}

\section{Experiment 1}

Sometimes when we remember things, we can recollect what happened at the time very vividly; other times we might know with certainty 
that something happened, but can't consciously recall the specifics of the episode in which it occurred. For each of the items you marked with a "yes" answer, I'm going to ask you to tell me whether you remember seeing that item as a picture or whether you know you saw it presented as a picture. "Remembering" an item means that you can consciously recall seeing that item as a picture. In other words, you can remember some aspect or aspects of what happened or what you experienced at the time the picture was presented. "Knowing" an item was presented means that although you believe the item was shown to you as a picture, you cannot consciously recollect what happened or what you experienced at the time you saw the picture.

\section{Experiment 2}

Sometimes when we remember things we've seen, we can recall seeing them very vividly; other times we might know with certainty that we saw something, but can't consciously recall the specifics of the episode in which it occurred. For each of these items, I'm going to ask you to choose between the following four responses: Whether you remember seeing that item as a picture, whether you know you saw it presented as a picture, whether the item was not shown to you as a picture, or whether you are not sure. "Remembering" an item means that you can consciously recall seeing that item as a picture. In other words, you can remember what the picture looked like. "Knowing" an item was presented means that although you believe the item was shown to you as a picture, you cannot consciously recollect what the picture looked like. You should choose the "not a picture" option when you believe that an item was a word or that the item was not shown to you at all. You should choose the fourth option, "not sure," only if you are not sure at all about whether your memory for the item corresponds to any of the first 3 choices.

(Manuscript received February 24, 1994; revision accepted for publication November 7,1994 .) 